\title{
IMPREGNATION OF POLY(METHYL
}

\section{METHACRYLATE) WITH CARBAMAZEPINE}

\section{IN SUPERCRITICAL CARBON DIOXIDE:}

\section{MOLECULAR DYNAMICS SIMULATION}

\author{
Darya L. Gurina ${ }^{1 *}$, Yury A. Budkov ${ }^{1,2}$, and Mikhail G. Kiselev ${ }^{1}$
}

${ }^{1}$ G.A. Krestov Institute of Solution Chemistry of the Russian Academy of Sciences, 1 Akademicheskaya St., Ivanovo 153045, Russian Federation; gdl@isc-ras.ru (D.G.); ybudkov@hse.ru (Y.B.); mgk@isc-ras.ru (M.K.)

${ }^{2}$ Tikhonov Moscow Institute of Electronics and Mathematics, National Research University Higher School of Economics, Tallinskaya st. 34, 123458 Moscow, Russian Federation *Correspondence: gdl@isc-ras.ru (D.G.); Phone.: +7-4932-351869 
Table 1S. Non-bonded energy parameters and partial atomic charges for used potential model of PMMA.

\begin{tabular}{|c|c|c|c|c|}
\hline & Atom & $\sigma, \mathbf{n m}$ & $\varepsilon, \mathrm{kJ} \mathrm{mol}^{-1}$ & q, e.c. \\
\hline & $\mathrm{C} 1$ & 0.350 & 0.276144 & -0.09 \\
\hline & $\mathrm{C} 2$ & 0.350 & 0.276144 & 0.00 \\
\hline & $\mathrm{C} 3$ & 0.350 & 0.276144 & -0.135 \\
\hline & $\mathrm{C} 4$ & 0.375 & 0.439320 & 0.51 \\
\hline & $\mathrm{C} 5$ & 0.350 & 0.276144 & 0.16 \\
\hline & $\mathrm{O} 1$ & 0.300 & 0.711280 & -0.33 \\
\hline H5 & $\mathrm{O} 2$ & 0.296 & 0.878640 & -0.43 \\
\hline$-\mathrm{c} 1-\mathrm{C} 2-$ & $\mathrm{H} 1, \mathrm{H} 2$ & 0.250 & 0.125520 & 0.045 \\
\hline 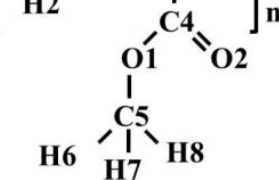 & $\begin{array}{l}\mathrm{H} 3, \\
\mathrm{H} 4, \\
\mathrm{H} 5\end{array}$ & 0.250 & 0.125520 & 0.045 \\
\hline & $\begin{array}{l}\text { H6, } \\
\text { H7, } \\
\text { H8 }\end{array}$ & 0.242 & 0.062760 & 0.03 \\
\hline
\end{tabular}

Table 2S. Non-bonded energy parameters and partial atomic charges for used potential model of CBZ.

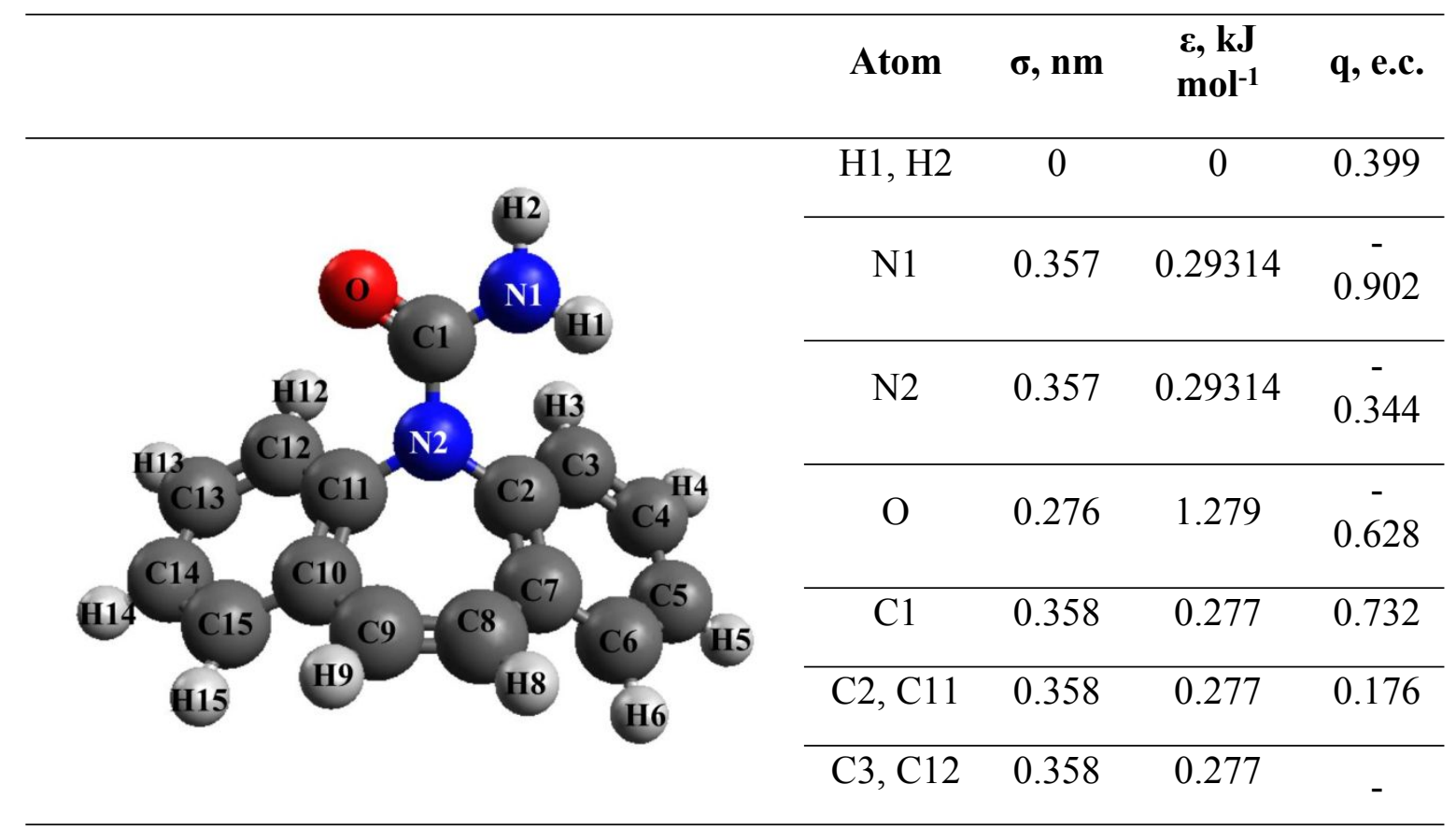




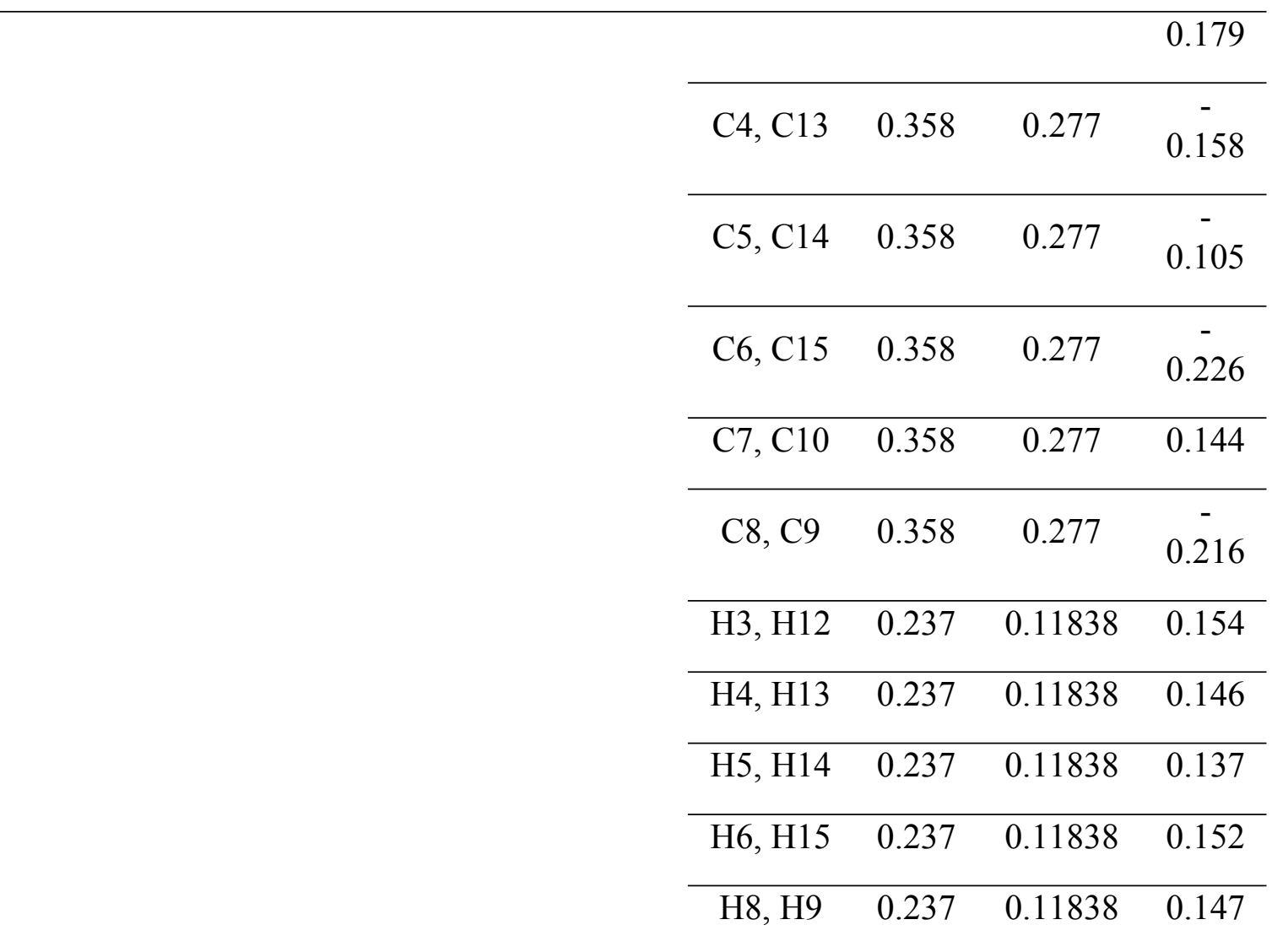

\section{The procedure of the PMMA swelling degree calculation}

As known limited swelling occurs over a long time and is determined by the rate of diffusion of the solvent molecules into the polymer. In the simplest case, the swelling process proceeds as a first-order reaction, therefore the swelling rate is equal to:

$$
\frac{d \alpha}{d t}=k\left(\alpha_{\max }-\alpha\right)
$$

where $k$ is the swelling rate constant, $\alpha_{\max }$ is the maximum degree of swelling.

Thus, the swelling kinetics equation has the following form:

$$
\alpha_{t}=\alpha_{\max }\left(1-e^{-k t}\right)
$$

Using equation (2), the degree of PMMA swelling obtained from MD by means of equation $\alpha=\frac{m-m_{0}}{m_{0}}=\frac{\left(m_{0}+m_{a d s}\right)-m_{0}}{m_{0}}=\frac{m_{a d s}}{m_{0}}$ was described as a function of time (Fig. 1S). The 
standard deviation was about 0.98 . Figure $1 \mathrm{~S}$ shows the coefficients of the swelling equation for the system.

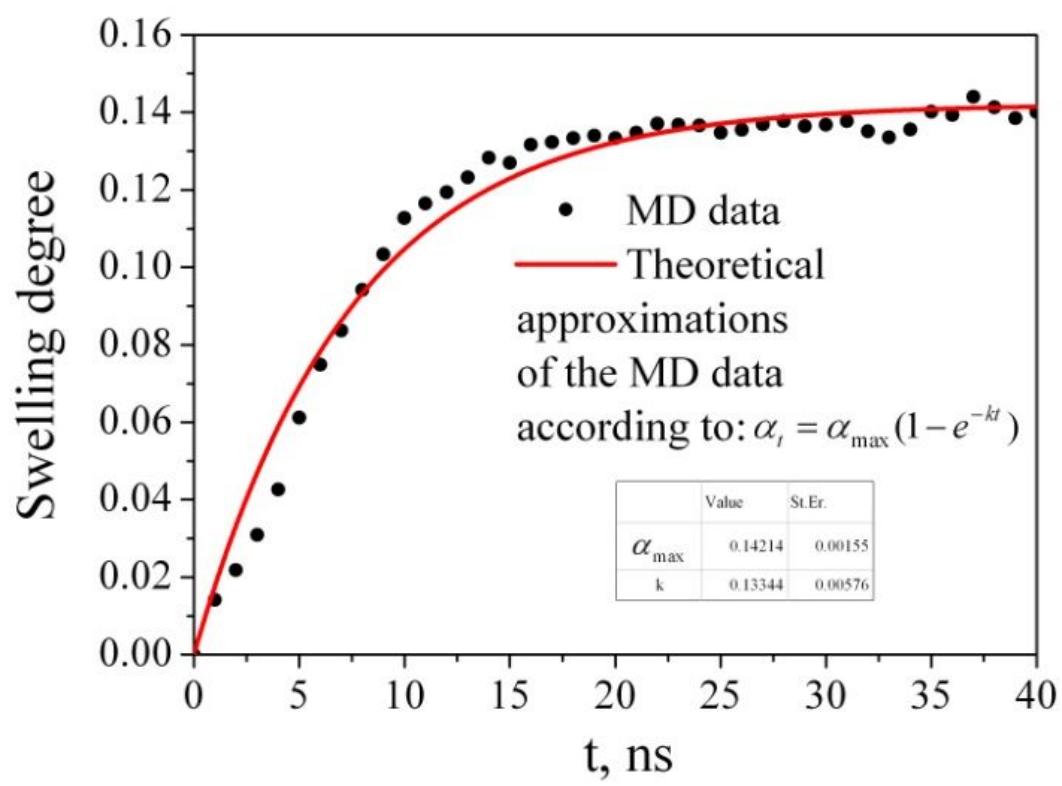

Figure 1S. Time dependence of polymer swelling degree (symbols) and theoretical approximations of the MD data according to Eqs. (2) (line). 